\title{
Expression of Catalase (CAT) and Ascorbate Peroxidase (APX) in MuSI Transgenic Tobacco under Cadmium Stress
}

\author{
Kye-Hoon Kim*, Young-Nam Kim, Ga Hee Lim, Mi Na Lee, and Yoon-Hwa Jung \\ Department of Environmental Horticulture, The University of Seoul, Seoul 130-743, Korea
}

\begin{abstract}
The MuSI is known as a multiple stress resistant gene with several lines. A previous study using RT-PCR showed that the expression of MuSI gene in tobacco plant induced its tolerance to Cd stress. This study was conducted to examine the enhanced Cd tolerance of the $M u S I$ transgenic tobacco plant through germination test and to understand the role of the involved antioxidant enzymes for the exhibited tolerance. Germination rate of MuSI transgenic tobacco was more than $10 \%$ higher than that of wild-type tobacco, and seedlings of MuSI transgenic tobacco grew up to 1.6 times larger and greener than seedlings of wild-type tobacco at 200 and $300 \mu \mathrm{M} \mathrm{Cd}$. From the third to the fifth day, CAT activities at 100 and $200 \mu \mathrm{M} \mathrm{Cd}$ and APX activities at 100, 200 and $300 \mu \mathrm{M}$ Cd of MuSI transgenic tobacco were up to two times higher than those of wild-type tobacco. MuSI gene is shown to enhance the activities of antioxidant enzymes resulting in higher tolerance to oxidative stress compared with the control plant.
\end{abstract}

Key words: MuSI transgenic tobacco, Cadmium resistance, Catalase (CAT), Ascorbate Peroxidase (APX)

\section{Introduction}

Soil contamination by human beings goes back as far as the Bronze Age (2500 B.C.) (Kabata-Pendias and Mukherjee, 2007). Early industrial activities such as mining and smelting of metalliferous ores, brick and pipe manufacturing as well as power generation and agricultural practices significantly contributed to soil contamination (Adriano, 1986; Cherian and Oliveira, 2005). Remediation of contaminated soil and water is a popular subject for both the scientific and the business communities. Phytoremediation is a promising soil remediation technique among many remediation techniques involving chemical, physical, biological and thermal means. One of the disadvantages of phytoremediation is the small amount of biomass of most hyperaccumulators. A plant with greater biomass and deep root system would be ideal for phytoremediation. As such plants are rare, scientists try to create new plants with the help of genetic engineering.

The MuSI is a gene with tolerance to a number of stresses including dehydration, salt, heavy metal, oxidation,

\footnotetext{
Received : January 20. 2011 Accepted : February 25. 2011

*Corresponding author : Phone: +82222102605

E-mail: johnkim@uos.ac.kr
}

and plant hormones. Several of its lines are extracted from sweet potatoes (Ipomoea batatas L. cv. Yulmi) (Seo et al., 2010). A previous study using RT-PCR showed that the expression of MuSI gene in tobacco plant induced its tolerance to cadmium stress. Seo et al. (2010) also showed that the seedlings of MuSI transgenic tobacco germinated and grew better than the seedlings of wild-type tobacco at MS medium containing 50 and $100 \mu \mathrm{M} \mathrm{Cd}$. Furthermore, in an experiment examining $\mathrm{Cd}$ tolerance of $\mathrm{MuSI}$ transgenic tobacco with a hydroponic system containing $\mathrm{Cd}, \mathrm{MuSI}$ transgenic tobacco showed resistance to cadmium at $200 \mu \mathrm{M} \mathrm{Cd}$ (Kim, 2010). Damages appeared in leaves of the wildtype tobacco induced by $\mathrm{Cd}$ toxicity continued through whole growth period showing chlorosis and withering, while $\mathrm{MuSI}$ transgenic tobacco was recovering from the $\mathrm{Cd}$ damage 10 days after $\mathrm{Cd}$ exposure.

When plants were exposed to cadmium toxicity, superoxide radicals generated in cells, and they were deformed to $\mathrm{H}_{2} \mathrm{O}_{2}$ by superoxide dismutase (SOD) (Dixit et al., 2001; Schützendüble and Polle 2002; Markovska et al., 2009). $\mathrm{H}_{2} \mathrm{O}_{2}$ is removed by CAT in peroxisomes and by the ascorbate-glutathione cycle where APX reduces it to $\mathrm{H}_{2} \mathrm{O}$ (Dixit et al., 2001; Mittler, 2002; Schützendüble et al., 2001; Vitoria et al. 2000). The objectives of this study were to determine 
enhanced $\mathrm{Cd}$ tolerance of $\mathrm{MuSI}$ transgenic tobacco through germination test and to understand the role of antioxidant enzymes for the $\mathrm{Cd}$ tolerance through hydroponic study.

\section{Materials and Methods}

Germination test This experiment was conducted with MuSI transgenic tobacco seeds and wild-type tobacco (control) seeds. MS mediums containing $\mathrm{Cd}$ at four different levels of concentration $(0,100,200$ and $300 \mu \mathrm{M})$ were prepared, and all four treatments were quintuplicated. Each treated medium was added in the petri dish (Ф10 $\mathrm{cm}$ ), and 20 seeds were placed in the medium with even distribution. Then the petri dish was sealed with plastic wrap, and placed in the incubator at $25^{\circ} \mathrm{C}$. The germinated seeds were counted 10 days after sowing. The growth parameters such as shoot/root length were determined for both group of tobacco plants 20 days after sowing.

Hydroponic culture Seedlings of MuSI transgenic tobacco and wild-type tobacco were cultured in a nutrient solution prepared according to Yamazaki's method (Yamazaki, 1982). The nutrient solution consisted of macro element $\left(\mathrm{NO}_{3}-\mathrm{N}, \mathrm{NH}_{4}-\mathrm{N}, \mathrm{P}, \mathrm{K}, \mathrm{Ca}, \mathrm{Mg}\right.$ and $\left.\mathrm{SO}_{4}-\mathrm{S}\right)$ and micro element $(\mathrm{Fe}, \mathrm{Cu}, \mathrm{B}, \mathrm{Mn}, \mathrm{Zn}$ and Mo), and was maintained at pH 5.8 and EC $1.2 \mathrm{dS} \mathrm{m}^{-1}$ during the cultivating period.

Prior to the exposure to $\mathrm{Cd}$, each seedling was transplanted to separate hydroponic containers and was acclimatized for five days. After the acclimation, the nutrient solution in each container was changed with another nutrient solution containing $\mathrm{Cd}$. These new nutrient solutions contained four different levels of $\mathrm{Cd}$ concentration at $0,100,200$ and $300 \mu \mathrm{M}$. Then the seedlings were grown for seven days with replacement of the $\mathrm{Cd}$ solution twice (three days interval) using deep flow technique (DFT).

Antioxidant enzymes (CAT and APX) The method by Sawada et al. (2008) was used to observe the activities of CAT and APX. The leaf tissues $(0.2 \mathrm{~g}$ FW) of MuSI transgenic tobacco and wild-type tobacco influenced by $\mathrm{Cd}$ exposure were ground with a mortar and pestle under chilled condition in homogenization buffer solution containing $25 \mathrm{mM}$ potassium phosphate (pH 7.8), $1 \mathrm{mM}$ ascorbic acid, $0.4 \mathrm{mM}$ ethylene diamine tetra-acetic acid (EDTA) and 2\% (w/v) polyvinylpolypyrrilidone. An aliquot $(1.5 \mathrm{~mL})$ of the homogenized mixture was centrifuged at $15,000 \mathrm{~g}$ for $20 \mathrm{~min}$ at $4{ }^{\circ} \mathrm{C}$. The supernatant was used for analyzing activities of CAT (EC 1.11.1.6) and APX (EC 1.11.1.11). The protein concentration of samples were measured by the Bradford's method (1976).

For the estimation of CAT activity, $0.1 \mathrm{ml}$ of extraction solution was added to $1.9 \mathrm{ml}$ of reaction buffer containing $50 \mathrm{mM}$ potassium phosphate $(\mathrm{pH} 7.0)$ and $10 \mathrm{mM}$ $\mathrm{H}_{2} \mathrm{O}_{2}$. And decomposition of $\mathrm{H}_{2} \mathrm{O}_{2}$ was determined at $240 \mathrm{~nm}$ for $1 \mathrm{~min}$ (Aebi, 1984).

For the estimation of APX activity, $0.1 \mathrm{ml}$ of extraction solution was added to $1.88 \mathrm{ml}$ of reaction buffer containing $25 \mathrm{mM}$ potassium phosphate ( $\mathrm{pH} 7.0$ ), $0.25 \mathrm{mM}$ ascorbic acid, $0.1 \mathrm{mM}$ EDTA and $0.02 \mathrm{ml}$ of $10 \mathrm{mM} \mathrm{H}_{2} \mathrm{O}_{2}$. And a decreased amount of the ascorbic acid was determined at $340 \mathrm{~nm}$ for $1 \mathrm{~min}$ (Nakano and Asada, 1981). The activities of CAT and APX and protein concentration of each sample were measured with a UV-visible spectrophotometer (UV-2500, Shimadzu, Japan).

\section{Results and Discussion}

Germination rate No differences in germination rate was observed between wild-type tobacco and $\mathrm{MuSI}$ transgenic tobacco in MS mediums with Cd levels of 0 and $100 \mu \mathrm{M}$. However, the germination rate of MuSI

Table 1. The component of nutrient solution according to Yamazaki's method.

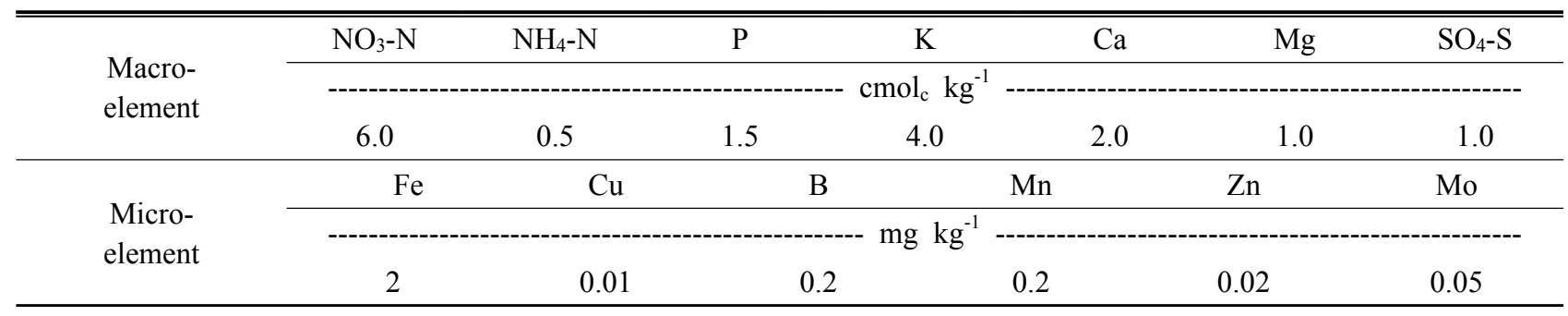


Table 2. Germination rate of MuSI transgenic tobacco and wild-type tobacco at 10 days after germination on MS medium containing $\mathrm{Cd}$. Values are expressed as the average \pm standard deviation of five media from each treatment.

(unit: \%)

\begin{tabular}{ccccc}
\hline \hline Treatment level $(\mu \mathrm{M})$ & 0 & 100 & 200 & 300 \\
\hline Wild-type tobacco & $90.7 \pm 3.4$ & $91.0 \pm 1.9$ & $70.0 \pm 3.5$ & $72.0 \pm 3.4$ \\
MuSI transgenic tobacco & $91.0 \pm 3.2$ & $90.0 \pm 4.2$ & $81.0 \pm 4.3$ & $88.0 \pm 2.0$ \\
\hline
\end{tabular}

Table 3. Length of seedling shoot of MuSI transgenic tobacco and wild-type tobacco on MS medium containing Cd after one month from gemination. Values are expressed as the average \pm standard deviation of eight seedlings from each treatment.

(unit: cm)

\begin{tabular}{ccccc}
\hline \hline Treatment level $(\mu \mathrm{M})$ & 0 & 100 & 200 & 300 \\
\hline Wild-type tobacco & $2.36 \pm 0.11$ & $2.70 \pm 0.10$ & $0.85 \pm 0.04$ & $0.38 \pm 0.02$ \\
$M u S I$ transgenic tobacco & $2.54 \pm 0.04$ & $2.46 \pm 0.05$ & $1.53 \pm 0.04$ & $0.55 \pm 0.02$ \\
\hline
\end{tabular}

transgenic tobacco was more than $10 \%$ higher than that of wild-type tobacco in MS mediums with $\mathrm{Cd}$ levels of 200 and $300 \mu \mathrm{M}$ (Table 2).

As $\mathrm{Cd}$ concentration increased, both tobaccos did not grow well. However, seedlings of MuSI transgenic tobacco grew 1.8 times $(200 \mu \mathrm{M} \mathrm{Cd})$ and 1.6 times (300 $\mu \mathrm{M} \mathrm{Cd}$ ) larger and greener than seedlings of wild-type tobacco after a month of sowing (Table 3; Fig. 1). This germination experiment confirmed that MuSI transgenic tobacco has higher tolerance to $\mathrm{Cd}$ than wild-type tobacco.

Activities of antioxidant enzyme In the previous hydroponic study, Kim (2010) showed both wild-type and MuSI transgenic tobaccos were initially damaged 2-3 days after Cd exposure. However, MuSI transgenic tobacco appeared to get recovered from $\mathrm{Cd}$ toxic symptom 10 days after $\mathrm{Cd}$ exposure while wild-type tobacco continued to be damaged through whole experiment period. During the one week antioxidant enzyme experiment, catalase (CAT) and ascorbate peroxidase (APX) activities of MuSI transgenic tobacco leaves increased more than those of wild-type tobacco leaves (Fig. 2 and Fig. 3). Between the third and the fifth day, CAT activity at 100 and $200 \mu \mathrm{M} \mathrm{Cd}$ and APX activity at 100, 200 and $300 \mu \mathrm{M} \mathrm{Cd}$ of MuSI transgenic tobacco were up to two times higher than those of wild-type tobacco. The experiment showed that the over-expression of MuSI gene enhanced antioxidant enzyme (CAT, APX) activities, which resulted in higher tolerance of MuSI transgenic tobacco to oxidative stress compared to the control plants (Fig. 2 and Fig. 3).
A
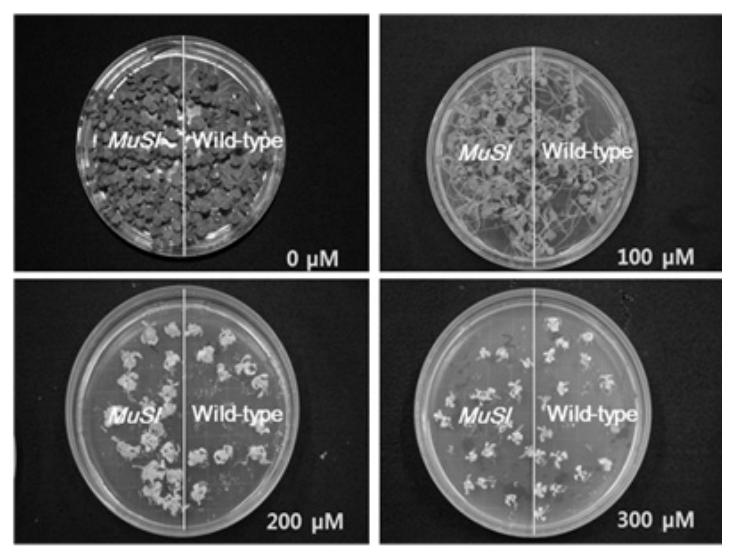

B
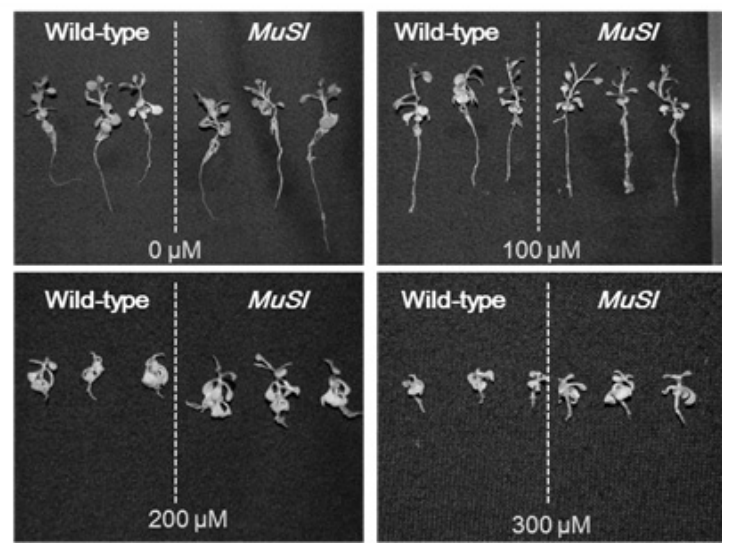

Fig. 1. Gemination of MuSI transgenic tobacco and wildtype tobacco on MS medium containing cadmium (0, 100, 200 and $300 \mu \mathrm{M})$. (A) Comparison of gemination for MuSI transgenic tobacco and wild-type according to Cd concentration at one month after gemination. (B) Comparison of growth for MuSI transgenic tobacco and wild-type according to $\mathrm{Cd}$ concentration at one month after germination. 

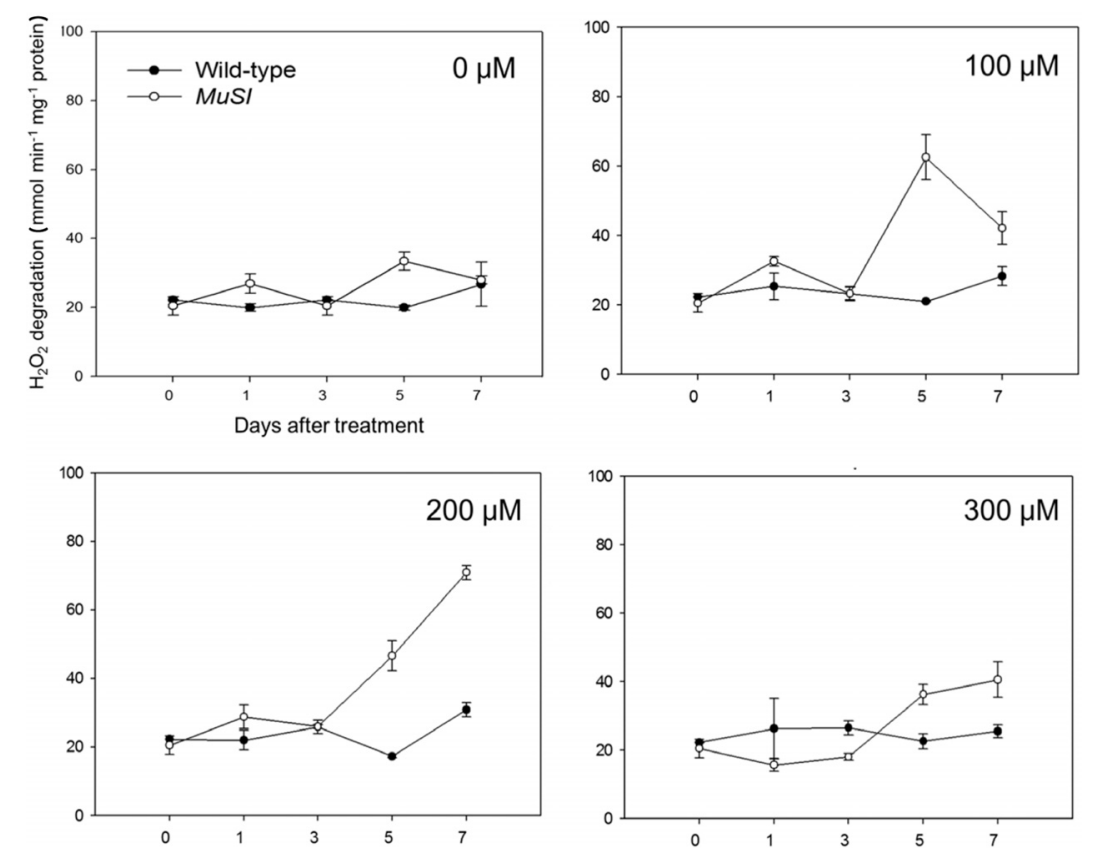

Fig. 2. Change of CAT activity in leaves of MuSI transgenic tobacco and wild-type tobacco treated with $0,100,200$ and $300 \mu \mathrm{M}$. Values are expressed as the average \pm standard deviation of three plant samples from each treatment.
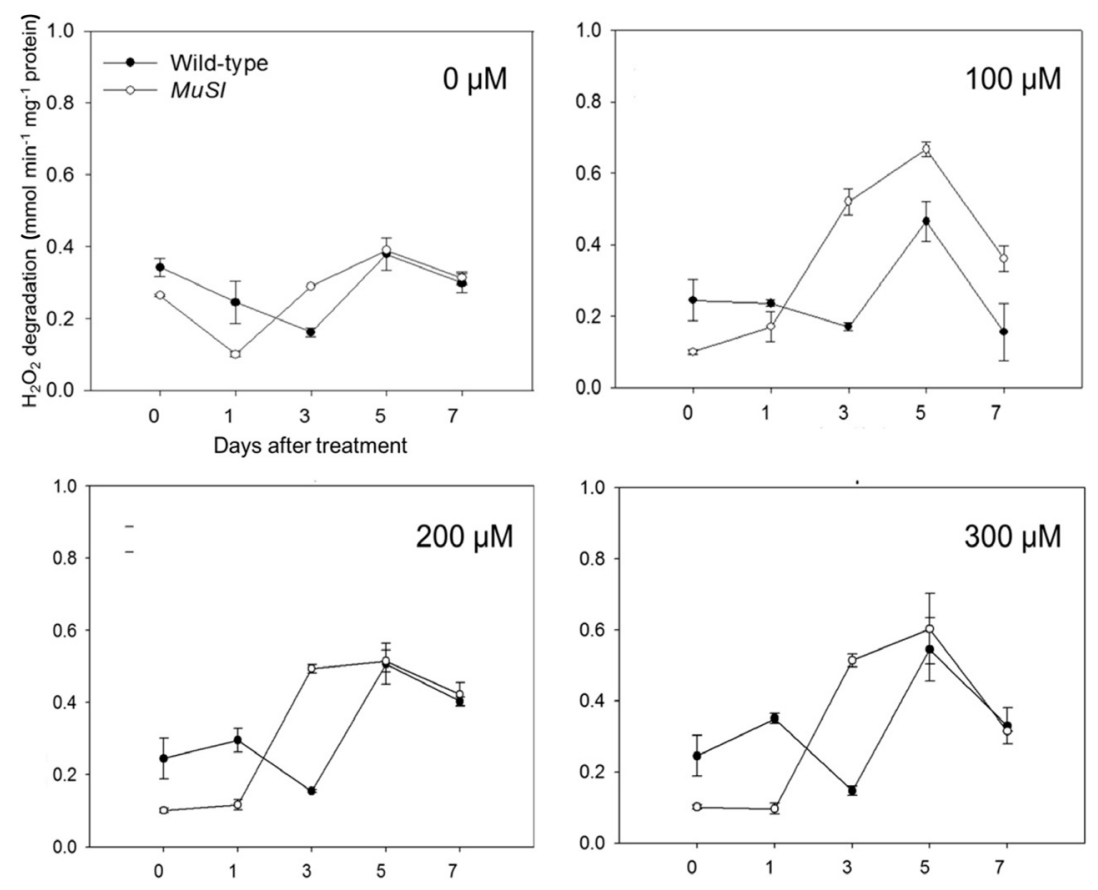

Fig. 3. Change of APX activity in leaves of MuSI transgenic tobacco and wild-type tobacco treated with $0,100,200$ and $300 \mu \mathrm{M}$. Values are expressed as the average \pm standard deviation of three plant samples from each treatment.

\section{Conclusions}

In conclusion, $\mathrm{MuSI}$ gene expressed tolerance to $\mathrm{Cd}$ stress. MuSI transgenic tobacco showed better visual growth under $\mathrm{Cd}$ treatment than wild-type tobacco. Also, MuSI transgenic tobacco induced more antioxidant enzymes such as catalase and ascorbate peroxidase compared to wild-type tobacco. The immediate mechanisms of MuSI transgenic plants for $\mathrm{Cd}$ tolerance such as phytochelatin and metallothionein should be identified through further studies. This study showed the potential of utilizing MuSI transgenic tobacco for phytoremediation of soils contaminated with $\mathrm{Cd}$. 


\section{Acknowledgement}

This work was supported by the University of Seoul 2009 Research Fund (research number: 200905041074).

\section{References}

Adriano, D.C. 1986. Trace element in the terrestrial environment. Springer-Verlag, New York.

Aebi, H. 1984. Catalase in virto: H. U. Bergmeyer and K. Gawehn (Ed) Methods of Enzymatic Analysis. Verleg Chemie, Weinheim. p. 673-684.

Bradford, M.M. 1976. A Rapid and Sensitive Method for the Quantitation of Microgram Quantities of Protein Utilizing the Principle of Protein-Dye Binding. Analytical Biochemistry 72:248-254.

Cherian, S. and M. Margarida Oliveira. 2005. Transgenic Plants in Phytoremediation: Recent Adavance and New Possibilities. Environmental Science \& Technology 39 (24): 9377-9390.

Dixit, V., V., Pandey, and R. Shyam. 2001. Differential antioxidative responses to cadmium in roots and leaves of pea (Pisumsativum L. cv. Azad). Journal of Experimental Botany 358:1101-1109.

Kabata-Pendias, A. and A.B. Mukherjee. 2007. Trace Elements from Soil to Human. Springer p. 294-308.

Kim, Y.N. 2010. Potential use of MuSI transgenic tobacco for phytoremediation of the soils contaminated with cadmium. MS. Thesis. The University of Seoul.

Markovska, Y.K., N.I. Gorinova, M.P. Nedkovska, and K.M.
Miteva. 2009. Cadmium-induced oxidative and antioxidant responses in Brassica juncea plants. Biologia Plantarum 53:151-154.

Mittler, R. 2002. Oxidative stress, antioxidants and stress tolerance. Trends in Plant Science 7:405-410.

Nakano, Y. and Y.K. Asada. 1981. Hydrogen peroxide is scavenged by ascorbate-specific peroxidase in spinach chloroplasts. Plant and Cell Physiology 22(5):867-880.

Sawada, H., I.S. Shim, K. Usui, K. Kobayashi, and S. Fujihara. 2008. Adaptative mechanism of Echinochloa crus-galli Beauv. var formosensis Ohwi under salt stress: Effect of salicylic acid on salt sensitivity. Plant Science 174:583-589.

Schützendüble, A., P. Schwanz, T. Teichmann, K. Gross, R. Langenfeld-Heyser, D.L. Godbold, and A. Polle. 2001. Cadmium-induced Changes in Antioxidative Systems, Hydrogen Peroxide Content, and Differentiation in Scots Pine Roots. Plant Physiology 127:887-898.

Schützendüble, A. and A. Polle. 2002. Plant reponses to abiotic stresses: heavy metal-induced oxidative stress and protection by mycorrhization. Journal of Experimental Botany 53:1351-1365.

Seo, S.G., J.S. Kim, Y.S. Yang, B.K. Jun, S.W. Kang, G.P. Lee, W. Kim, J.B. Kim, H.U. Lee, and S.H. Kim. 2010. Cloning and characterization of the new multiple stress responsible gene I ( $M u S I)$ from sweetpotato. Genes \& Genomics 32:544-552.

Vitoria, A.P., P.J. Lea, and R.A. Azevedo. 2000. Antioxidant enzymes reponses to cadmium in radish tissues. Phytochemistry 57:701-710.

Yamazaki, K. 1982. Nutrient Solution Culture (in Japanese). p. 251. Pak-kyo Co., Tokyo, Japan. 